\title{
ENVIRONMENTAL BENEFITS FROM CO 2 REDUCTION \\ DUE TO MODAL REPLACEMENT: A LIGHT RAIL VEHICLE CASE STUDY IN BRASILIA CITY
}

\author{
Paulo Henrique da Silva Costa \\ Leisy Mikaelly Alves Teixeira \\ Janaína Cardoso Pinheiro \\ Fabiana Serra de Arruda \\ Augusto César de Mendonça Brasil \\ University of Brasília - UnB, Brazil
}

\begin{abstract}
This work aims to measure the reduction of Carbon Dioxide $\left(\mathrm{CO}_{2}\right)$ emissions in atmosphere by replacing the modal urban bus by Light Rail Vehicle (VLT). In order to accomplish this objective, a case study in Brasilia, Federal District, in the stretch of VLT which passes on Via W-3 South was conducted. The Theory of Externalities that discusses the right to ownership of private and public goods and responsibilities about the positive and negative externalities caused by the agents and individuals of society was used to support the analyses. It was used the Top-Down method, which allowed the calculation the direct emissions of $\mathrm{CO}_{2}$. The values obtained on the reduction of $\mathrm{CO}_{2}$ emissions were converted into values of carbon credits as a way to economically measure such reductions. The results showed a significant reduction in $\mathrm{CO}_{2}$ emissions per year and consequent environmental benefit.
\end{abstract}

\section{INTRODUCTION}

The transport sector is one of the major contributors to air pollution in the world due to emissions of polluting gases, especially carbon dioxide $\left(\mathrm{CO}_{2}\right)$ causing environmental, health and quality of life damage to the population. Regarding environmental pollution caused by motorized road vehicles, Brasil (2006) states that the use of fossil fuels is the main factor responsible for poor air quality in cities. Emissions such as hydrocarbons and nitrogen oxides cause irritation in the eyes and the respiratory system, producing allergies, asthma, chronic bronchitis and reducing visibility. Thus public policies and the decision-making process on the choice of the mode of transport should consider the external factors specific to each mode.

Among the modes of transportation, the electric light rail vehicle (VLT) stands out in the field of mass transport as an alternative for highly urbanized locations with the presence of large agglomerations of people. This mode significantly contributes towards reducing the emission of carbon dioxide $\left(\mathrm{CO}_{2}\right)$ because, besides having a low emission level, it avoids the emissions that would be produced if their passengers, for lack of a less polluting mode of transport, had to use more polluting modes of transport, such as buses or private vehicles.

This work aims to measure the potential environmental and economic benefits arising from the implementation of the VLT to replace buses. In order to achieve the goal proposed, $\mathrm{CO}_{2}$ 
emission reduction was calculated considering the use of the VLT in place of buses on a specific route in Brasília, Federal District. The environmental benefit from the reduction of $\mathrm{CO}_{2}$ emissions was converted into carbon credits which are one of the ways to compensate for the environmental damage via Clean Development Mechanism (CDM) projects.

The adopted methodology uses an adapted version of the Top Down method to estimate $\mathrm{CO}_{2}$ emissions developed by the IPCC (Intergovernmental Panel on Climate Change) and presented in the IPCC Guide lines for National Greenhouse Gas Inventories (IPCC, 1996).

\section{MATERIALS AND METHODS}

The VLT of Brasilia is intended to ease the flow of vehicles on the roads where it will be deployed and enhance the public transport system of the city. The project proposes two lines: Line One is expected to be $22.6 \mathrm{~km}$ long and divided into three stretches: Stretch 1: Airport -South Wing Terminal-6.5 km; Stretch 2: Terminal 2 - South Wing-502 North - 8.7 km; and Stretch 3: 502 North-Wing - North Terminal - 7.4 km. Line Two - Monumental Axis, will link the International Airport to the South and North Wings and the Central Region, passing by the Hotel and Commercial areas North and South, as can be seen in Figure 1:

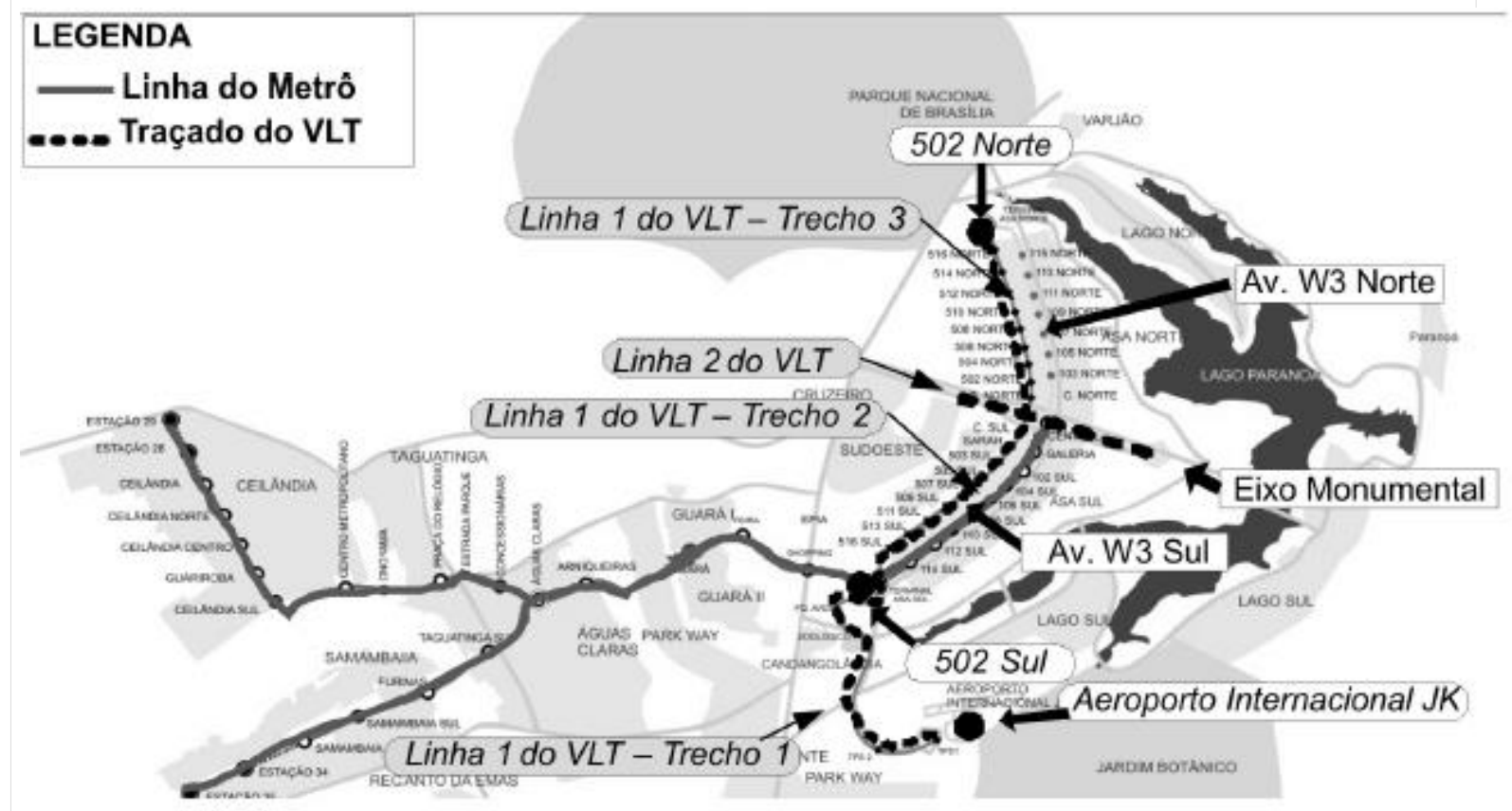

Figure 1-Route planned for the VLT and Subway Line Brasilia - DF. Source: Santos, Taco and Silva (2009).

With the deployment of the VLT there will be a gradual reduction of the buses that circulate in this region and that will represent a significant decrease in air pollution stemming from vehicle emissions.

Public policies and the decision-making process on the choice of the mode of transport should consider the external factors specific to each of these modes. The most problematic of the externalities is right of ownership leading to inefficient production of externalities. As 
in the case of pollution of the environment, people and companies believe they can pollute the air and natural resources of the environment because the right to ownership is not well defined.

Coase's Theorem (Coase, 1960) fits in with a solution to the market's failures concerning externalities insofar as property rights are properly defined in a manner that allows the establishment of legal negotiating mechanisms between the parties. In this approach, property rights provide the answer to the problems generated by externalities. Such an approach is only applied when the rights or ownership of an individual or company are infringed on.

According to Coase (1960), the difficulty of enforcing property rights hinders negotiations between the parties involved in the problem. One of the big problems is the difficulty of measuring the value of the prejudice or benefit and so delimiting the rights of ownership without the existence of a correct evaluation of this externality is a delicate process.

Article 12 of the Kyoto Protocol in the United Nations Fourth Convention on climate change, set out a mechanism called the Clean Development Mechanism (CDM) for the financing of projects that can generate certified emission reductions (CERs-Certified Emission Reductions) that are credited to QELROs (Quantified Emission Limitation and Reduction Commitments), from the investor country (Kyoto Protocol, 1997). The assessment is made in terms of carbon credits that are traded between countries of the same carbon market. CDM projects can be implemented in the sectors of energy, transport and forestry.

In this work, we used an adaptation of the Top Down Method to calculate the amount of $\mathrm{CO} 2$ emitted by buses and microbuses circulating in Via W-3 South in Brasilia. The Top Down Method to estimate $\mathrm{CO}_{2}$ emissions was presented in the IPCC Guide lines for National Greenhouse Gas Inventories (IPCC, 1996). The method consists of six steps: Step 1-Estimate the apparent fuel consumption in original units; Step 2-Convert to a Common Energy Unit; Step 3-Multiply by Emission Factors to calculate the carbon content; Step 4 - Calculate the Carbon Stored; Step 5- Adjust for non oxidized carbon; Step 6-Convert the oxidized carbon to $\mathrm{CO}_{2}$ Emissions.

133 bus lines operated by 5 companies pass through Via W-3 South, the object of this study. These lines are operated by two types of vehicles (city buses and microbus) and perform $1,105,156$ trips a year totaling 10,375,324 $\mathrm{km}$ annually and consuming approximately $4,380,989$ liters of diesel per year. Table 1 presents the annual number of trips, the annual mileage traveled and the annual diesel consumption by type of vehicle. Table 2 presents the results of the calculation of $\mathrm{CO}_{2}$ emissions:

\begin{tabular}{cccc}
\hline Vehicles & Trips/year & km/year & $\begin{array}{c}\text { Liters of } \\
\text { diesel/year }\end{array}$ \\
\hline City bus & 994,240 & $9,617,730$ & $4,181,622$
\end{tabular}


Microbus

110,916

757,594

199,367

Total

$1,105,156$

$10,375,324$

$4,380,989$

Table 1: Public passenger transport Via W-3 South of the city of Brasília.

\begin{tabular}{l|c}
\hline Liters of diesel/year & $4,380,989$ \\
\hline $\mathrm{m}^{\mathbf{3}}$ & $4,381.1$ \\
\hline Energy $(\mathrm{TJ})$ & 152,930 \\
\hline Amount of Carbon $(\mathrm{GgC})$ & 3.0892 \\
\hline Liquid Emmisions of Carbon $(\mathrm{GgC})$ & 3.0892 \\
\hline Actual Emmisions of carbon $(\mathrm{GgC})$ & 3.058308 \\
\hline Actual Emissions of carbono dioxide $(\mathbf{t C O})$ & $\mathbf{1 1 , 2 1 3 . 8 0}$ \\
\hline
\end{tabular}

Table 2: Diesel consumption and carbon emissions by buses that travel on Via W-3 South

After converting the diesel consumption into carbon and carbon dioxide emissions these emissions were converted into carbon credits per year obtaining a value equivalent to $\mathrm{R} \$$ 198,133.27. This value could be negotiated through the implementation of Clean Development Mechanisms.

\section{RESULTS AND DISCUSSION}

Modal substitution policies that meet the needs of users of public transport more effectively and the implementation of policies for the reduction of pollutant emissions and compensation of those emissions are of the utmost importance. This study aimed to estimate the environmental benefits of modal replacement of buses by Light Rail Vehicle on a busy stretch of the city of Brasília.

The results showed that this modal replacement would avoid the emission of 11,213.80 tons of carbon per year. This reduction in emissions is an environmental benefit, offering the local population less pollutants in the air, with consequent improvement in quality of life. In addition, this emission economy could be inserted in Clean Development Mechanism projects in order to be traded on the world market in the form of carbon credits. The values in carbon credit calculated for modal replacement were in the range of 198,133.27 Brazilian reals per year for the stretch of the Via W-3 South analyzed. It is noteworthy that this is the value of the environmental benefit of only one of the three routes planned for deployment of the VLT in Brasilia.

The survey results corroborate the Theory of Externalities insofar as the action of the bus companies providing public transport service for the population discharges pollutants in the air impacting the well-being of individuals in their environment, whether they are users of this mode of transport or not. This fact constitutes a negative externality of public transport. In the absence of any financial transaction with impacts on the well-being of individuals, there is a market failure. One of the ways to solve such problems, according to the Austrian School, is to define ownership rights. 
This study has its limitation in the fact of having only calculated the environmental benefits of carbon emissions that will no longer be issued in a certain stretch operating VLT in Brasília in the case of modal replacement. Also, by the fact that it calculates emissions only the in form of carbon credits, i.e. only considering emissions of carbon dioxide. This is due to the difficulty of measuring and monetizing the losses caused by negative externalities from pollutant emission from road transport that uses fossil fuel. In other words, other ways to monetize the negative externalities caused by the emission of other pollutants from transport mode, or the remuneration of the positive externalities to stop emitting such pollutants are still merely incipient and underperforming.

These limitations are constituted as gaps in future studies and in the development of public policies to mitigate environmental pollution by delimiting the ownership rights to pollute the air and developing financial relations between these rights such as non-pollution enforcement and incentives for environmental preservation.

\section{REFERENCES}

BRASIL. Ministério das Cidades (2006). Mobilidade e Desenvolvimento urbano/Ministério das Cidades, Secretaria de Transporte e da Mobilidade Urbana. Brasília: MCidades, 2006. (Gestão Integradas da Mobilidade Urbana, 1) 164 Páginas: Il.; 30cm. CDU 338.47:711.

COASE, R. H. (1960). The problem of social cost. Journal of Law and Economics 3, 1-44.

IPCC (1996). Greenhouse gas inventory reporting instructions - IPCC Guidelines for national greenhouse gas inventories. Vol 1, 2, 3. Intergovernmental Panel on Climate Change, United Nations Environment Program, the Organization for Economic Cooperation and Development and the International Energy Agency, London. $3 \mathrm{v}$.

KYOTO PROTOCOL. (1997). The Kyoto Protocol to the United Nations Framework Convention on Climate Change. Kyoto: UNEP/WMO.

SANTOS, L. S.; TACO, P. W. G.; SILVA, A. H. (2009). Análise do Comportamento de Viagens dos Possíveis Usuários de Um Veículo Leve Sobre Trilhos na Avenida W3Brasília-DF. $5^{\circ}$ Concurso de monografia CBTU 2009 - A Cidade nos Trilhos. Brasília, Brasil. 